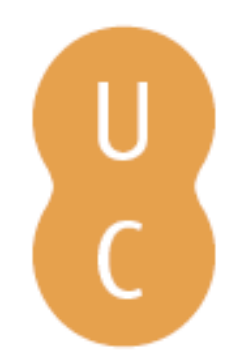

\title{
nommalina
}

\section{Condicionalismo climático dos terrenos poligonais em vénus, na terra e em marte}

\author{
Autor(es): $\quad$ Reis, P. A.; Alves, E. I.; Barata, M. T.
}

Publicado por: Imprensa da Universidade de Coimbra

URL

persistente: URI:http://hdl.handle.net/10316.2/31377

DOI: $\quad$ DOI:http://dx.doi.org/10.14195/978-989-26-0534-0_1

Accessed : $\quad$ 26-Apr-2023 12:44:13

A navegação consulta e descarregamento dos títulos inseridos nas Bibliotecas Digitais UC Digitalis, UC Pombalina e UC Impactum, pressupõem a aceitação plena e sem reservas dos Termos e Condições de Uso destas Bibliotecas Digitais, disponíveis em https://digitalis.uc.pt/pt-pt/termos.

Conforme exposto nos referidos Termos e Condições de Uso, o descarregamento de títulos de acesso restrito requer uma licença válida de autorização devendo o utilizador aceder ao(s) documento(s) a partir de um endereço de IP da instituição detentora da supramencionada licença.

Ao utilizador é apenas permitido o descarregamento para uso pessoal, pelo que o emprego do(s) título(s) descarregado(s) para outro fim, designadamente comercial, carece de autorização do respetivo autor ou editor da obra.

Na medida em que todas as obras da UC Digitalis se encontram protegidas pelo Código do Direito de Autor e Direitos Conexos e demais legislação aplicável, toda a cópia, parcial ou total, deste documento, nos casos em que é legalmente admitida, deverá conter ou fazer-se acompanhar por este aviso.

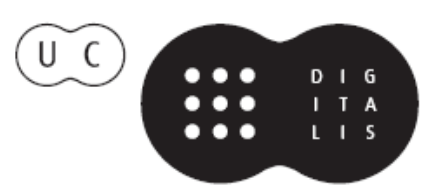





\title{
CONDICIONALISMO CLIMÁTICO DOS TERRENOS POLIGONAIS EM VÉNUS, NA TERRA E EM MARTE
}

\author{
CLIMATIC CONDITIONING OF POLYGONAL \\ TERRAINS ON VENUS, EARTH, AND MARS
}

Resumo - Os planetas telúricos possuem semelhanças a nível morfológico e estrutural que permitem considerá-los como um todo, apesar de particularidades como a massa, o volume, o clima e a geomorfologia. Uma feição geomorfológica peculiar, os terrenos poligonais, é observável quer em Vénus, planeta "quente", quer em Marte, planeta “frio", bem como na Terra, seja em climas frios ou quentes. A distribuição diferencial de propriedades geométricas destas estruturas superficiais em climas "quentes" (Vénus e deserto do Arizona) e climas "frios" (Marte e Svalbard - Ártico), permite reconhecer a importância da interação entre atividade geológica e clima na formação e desenvolvimento das referidas estruturas.

Palavras-chave - Terrenos poligonais; Climatologia comparada; Alteraçôes globais; Geologia planetária

Abstract - Terrestrial planets display morphological and structural similarities which allow considering them as a whole in spite of particularities such as mass, volume, climate and geomorphology. A peculiar geomorphologic feature, polygonal terrain, is present on Venus, a "hot" planet, on Mars, a "cold" planet, and on Earth, both on cold and warm climates. The differential distribution of geometric properties of these features in "hot" climates (Venus and Arizona desert) and "cold" climates (Mars and Svalbard-Arctic), evidences the importance of the interaction between geologic activity and climate in the formation and evolution of those structures.

Keywords - Polygonal terrain; Compared climatology; Global change; Planetary geology

${ }^{1}$ Centro de Geofísica da Universidade de Coimbra, Av. Dias da Silva, 3000-134 Coimbra, Portugal; paulaareis@gmail.com; mtbarata@gmail.com

2 Instituto Geofísico, Centro de Geofísica e Dep. Ciências da Terra da Universidade de Coimbra, Av. Dias da Silva, 3000-134 Coimbra, Portugal; livo@ci.uc.pt 


\section{1 - Introdução}

Tendo em conta as condições de formação do Sistema Solar, os planetas telúricos possuem semelhanças a nível morfológico e estrutural que permitem estudá-los como um todo. No entanto, apresentam particularidades, como a massa, o volume, a atmosfera e as estruturas superficiais.

Apesar de única, a Terra partilha diversas características com os restantes planetas telúricos ou terrestres - Mercúrio, Vénus e Marte. São planetas rochosos, total ou maioritariamente sólidos, com elevada densidade, possuindo atmosfera que representa uma pequeníssima parte das suas massas totais. Entre todas as atmosferas, a de Vénus é a mais densa.

Para além disto, os planetas telúricos estiveram sujeitos a períodos de atividade geológica o que alterou de forma muito profunda as suas estruturas internas.

O clima atual de Vénus resulta da interação entre um efeito de estufa eficaz e as propriedades radiativas da sua cobertura nebulosa, pois ambos são suscetíveis às alteraçôes da abundância do vapor de água atmosférico e dos gases sulfurosos presentes na atmosfera deste planeta. A ocorrência de processos à escala planetária, que envolvem a circulação e captura destes voláteis afeta a sua abundância, ao longo do tempo, provocando alteraçóes climáticas.

A temperatura média da Terra $\left(15^{\circ} \mathrm{C}\right)$ permite a existência de água no estado líquido, o que é fundamental para a existência de vida. Essa temperatura média é o resultado da interação da atmosfera (principalmente dos gases de efeito de estufa) e da geologia terrestre.

Marte é um dos planetas mais facilmente observáveis da Terra, à vista desarmada. Possui condiçóes ambientais que quase permitem a existência de vida (como a conhecemos), pois a sua atmosfera contém grandes quantidades de água e a temperatura pode chegar aos $20^{\circ} \mathrm{C}$ (ALVES, 2010).

São dois os modelos propostos para a formação de estruturas poligonais em Vénus: arrefecimento seguido de aquecimento (litosférico) acima de uma intrusão (SMREKAR et al., 1992) e arrefecimento como resposta à alteração climática (BULLOCK \& GRINSPOON, 2001). Este último pode explicar a formação daquelas estruturas na ausência de campos de tensão.

Terra e Vénus têm aproximadamente o mesmo tamanho e composição; no entanto, tiveram desenvolvimentos completamente diferentes.

Vénus é um planeta bastante hostil. A sua temperatura atmosférica média de $460^{\circ} \mathrm{C}$ é claramente superior à da Terra. Quanto à pressão do ar à superfície é quase 100 vezes superior à da Terra, o que é da mesma ordem de grandeza da pressão vigente a $1 \mathrm{~km}$ de profundidade nos oceanos terrestres. Quanto às crateras e aos vulcóes, estes estão completamente envolvidos por espessas nuvens de ácido sulfúrico, sendo que as suas estruturas à superfície apenas são reveladas em imagens de radar (ALVES, 2010).

Marte também atravessou transformaçôes extremas do clima. O interior de Marte é, hoje, demasiado frio para que o vulcanismo esteja ativo, sendo a sua superfície coberta por gelo. No entanto, apesar das variaçóes nos movimentos translacionais e rotacionais de Marte poderem induzir mudanças climáticas no próprio planeta, o vulcanismo não voltará a ter um papel ativo. Relativamente à Terra e a Vénus, estes possuem climas induzidos pela interação dinâmica entre processos geológicos e atmosféricos, pelo que variaçóes climáticas são constantes nestes dois planetas.

$\mathrm{Na}$ atualidade, o clima de Vénus é controlado por dois processos principais: o aquecimento global, consequência do efeito de estufa $\left(\mathrm{CO}_{2}\right)$, e o arrefecimento, devido à reflexão 
da radiação solar pela cobertura nebulosa permanente. $\mathrm{O}$ aumento de quantidades de água acima dos valores atuais terá levado ao aquecimento por efeito de estufa, e à diminuição da espessura das nuvens, devido à evaporação das camadas nebulosas mais próximas da superfície. No entanto, as enormes quantidades de $\mathrm{SO}_{2}$ atmosférico podem arrefecer o planeta, devido ao espessamento dessas mesmas nuvens e ao consequente aumento da sua refletividade (BULLOCK \& GRINSPOON, 2001).

$\mathrm{O}$ estudo das geoformas presentes nos diversos planetas pode ser feito através de um processo de comparação com estruturas existentes no planeta Terra. Conhecendo as estruturas, é possível inferir os processos que as originaram, partindo do princípio que as forças e os processos que ocorrem na Terra se podem aplicar a outros planetas.

No presente trabalho testou-se a hipótese de a geometria dos terrenos poligonais ser condicionada pelo clima. Para esse efeito, compararam-se imagens de terrenos poligonais num planeta "quente" (Vénus) e num planeta "frio" (Marte) com imagens de terrenos poligonais frios e quentes na Terra.

\section{2 - Propriedades geométricas de terrenos poligonais em Vénus, na Terra e em Marte}

O estudo das geoformas presentes nos diversos planetas pode ser feito através de um processo de comparação com estruturas existentes no planeta Terra. Conhecendo as estruturas, é possível inferir os processos que as originaram, partindo do princípio que as forças e os processos que ocorrem na Terra se podem aplicar a outros planetas.

Assim, foram previamente selecionadas imagens de deteção remota de cada um dos planetas/regióes em estudo: Vénus (Fig. 1), Terra (Arizona - Fig. 2 - e Svalbard, Ártico Fig. 3) e Marte (Fig. 4).

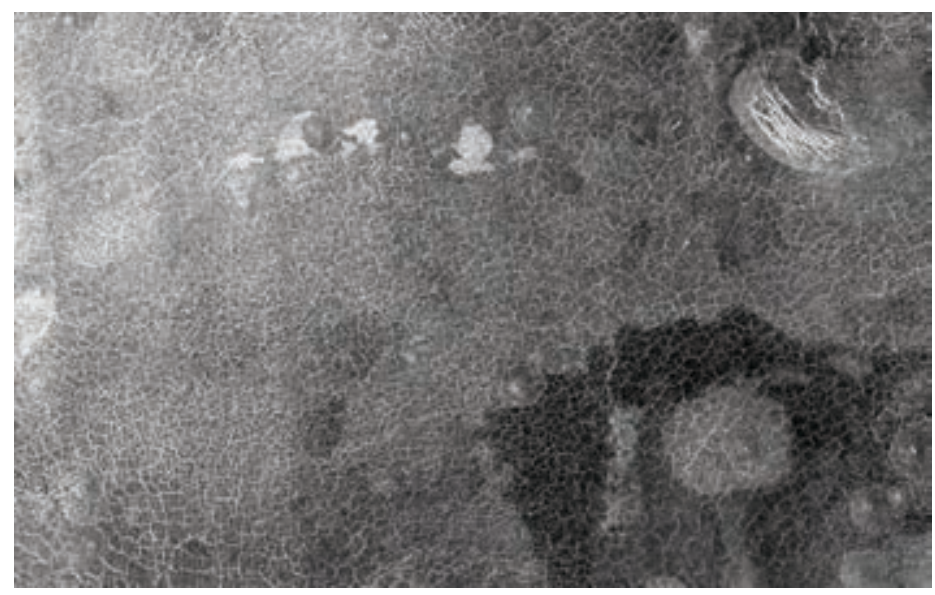

Fig. 1 - Terrenos poligonais em Vénus (região de Hecate Chasma - $15^{\circ} \mathrm{N} ; 266^{\circ} \mathrm{E}$ ).

A imagem tem $1650 \mathrm{~m}$ de largura - Magellan/NASA/JPL - NASA (2012). 


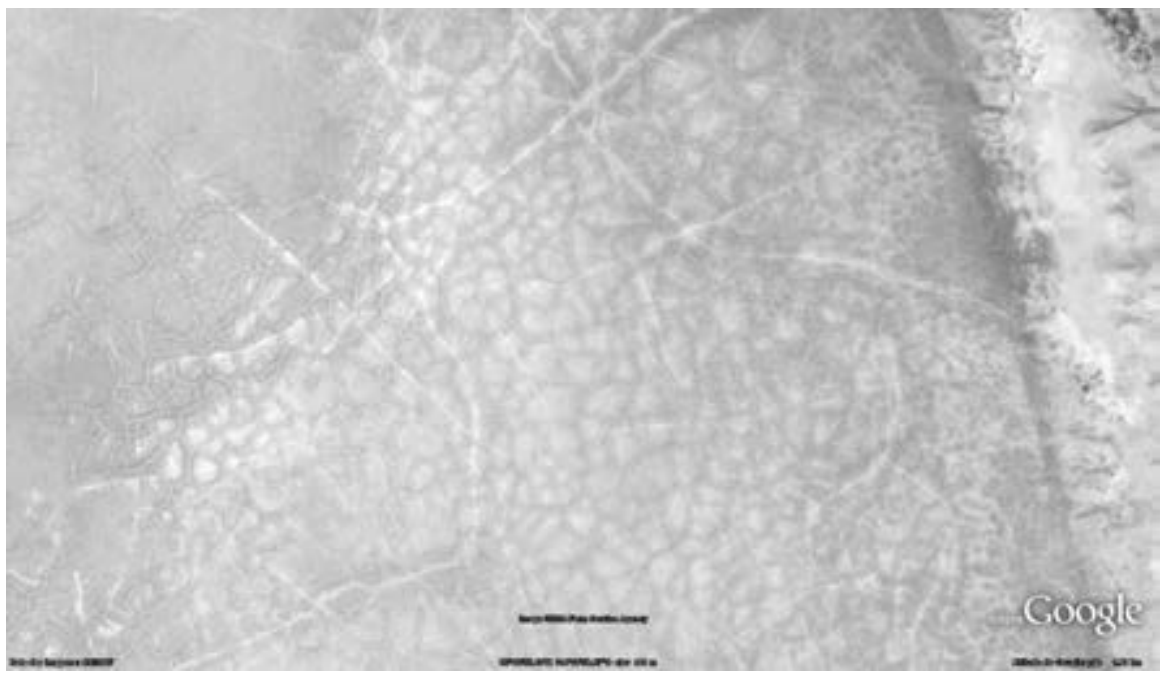

Fig. 2 - Terrenos poligonais no Arizona - Terra ( $\left.35^{\circ} 40^{\prime} 55^{\prime \prime} \mathrm{N} ; 114^{\circ} 01^{\prime} 58^{\prime \prime} \mathrm{W}\right)$. A imagem tem $1330 \mathrm{~m}$ de largura. GOOGLE INC. (2012).

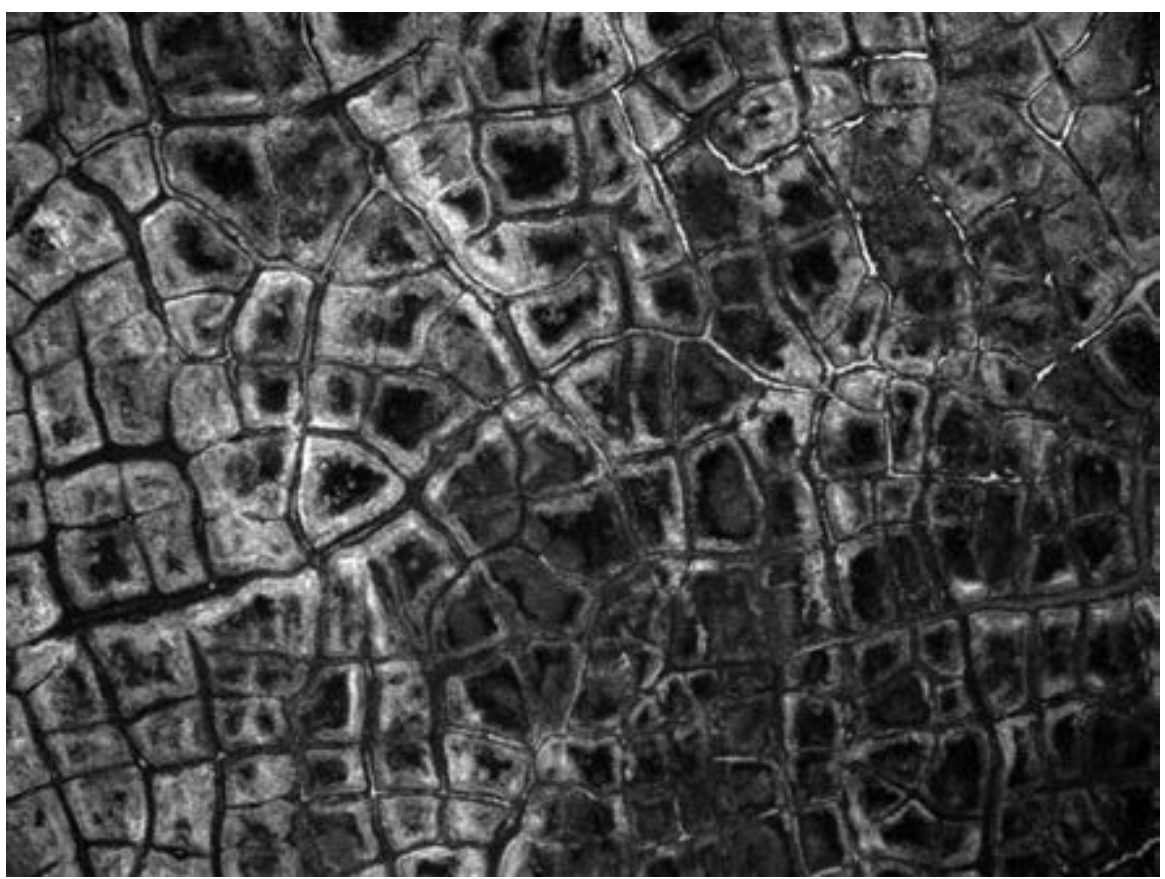

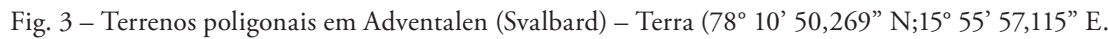
A imagem tem $240 \mathrm{~m}$ de largura. GOOGLE INC. (2012). 


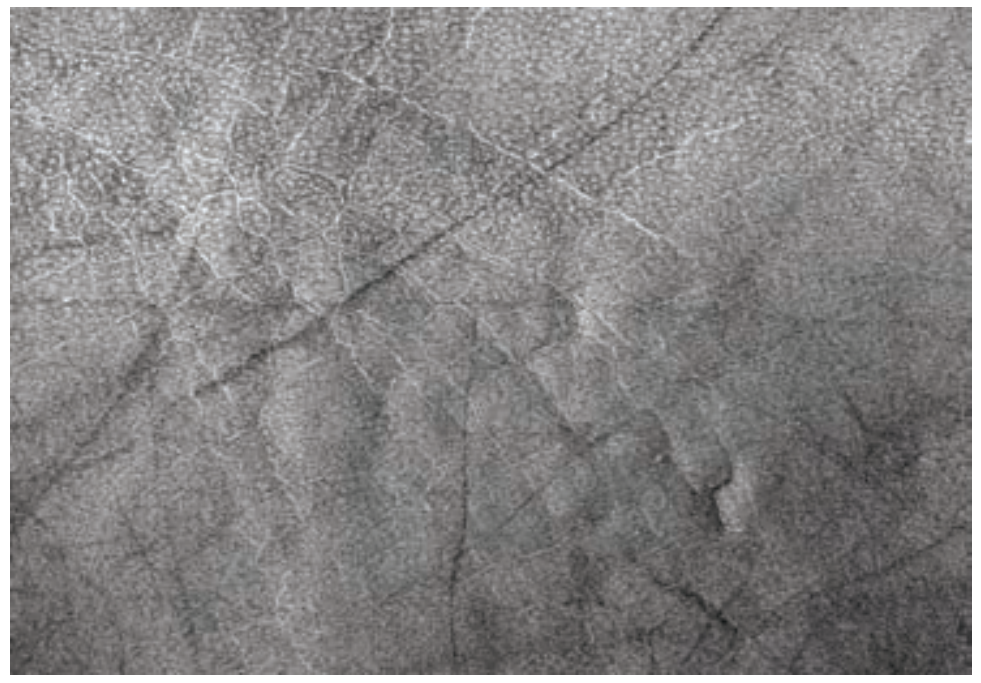

Fig. 4 - Terrenos poligonais em Marte (centro em $57,0^{\circ} \mathrm{N} ; 353,5^{\circ} \mathrm{E}$ ).

A imagem tem $850 \mathrm{~m}$ de largura. NASA/JPL/U. Arizona, NASA (2012).

Recorrendo ao programa de fonte aberta Quantum GIS (http://www.qgis.org/), foram calculados os perímetros, as áreas e o número de lados dos polígonos em cada uma das imagens de deteção remota das Figs. 1 a 4.

Com os dados obtidos, elaborou-se um gráfico que estabelece a correlação entre os perímetros e as áreas dos polígonos estudados (Fig. 5).

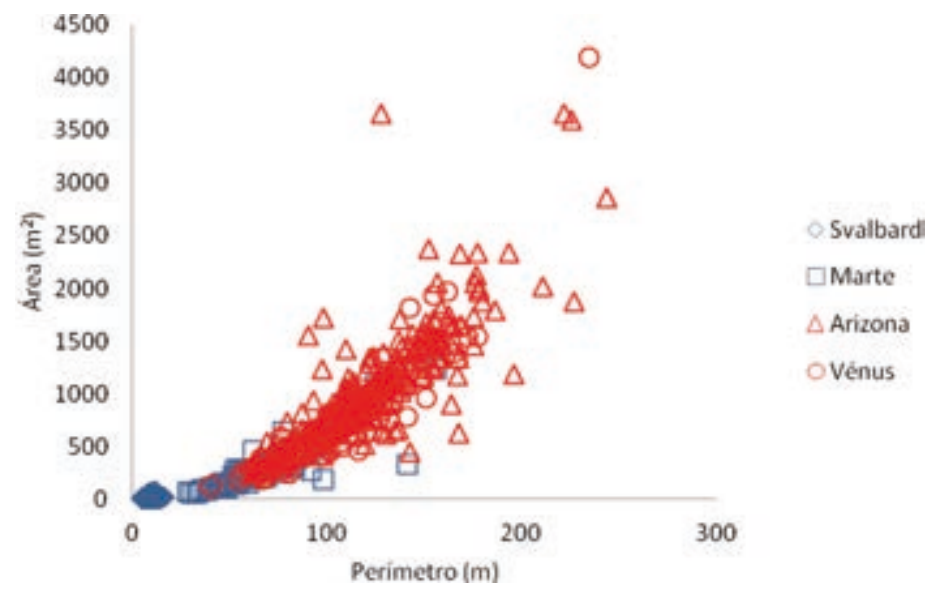

Fig. 5 - Correlação entre os perímetros e as áreas de terrenos poligonais em cada imagem estudada. 
Pela análise da Fig. 5 é evidente uma distribuição diferencial dos valores dos perímetros e áreas de polígonos nas regiôes/planetas frios (Svalbard e Marte) e nas regiōes/ planetas quentes (Arizona e Vénus).

No caso dos polígonos venusianos, de entre os vários tipos existentes, foi selecionado um conjunto de polígonos que não estão sob a influência de campo de tensão regional, pelo que são mais uniformes, e cuja formaçáo pode ser explicada num cenário de variação climática (BULLOCK \& GRINSPOON, 2001), ou seja, estas estruturas foram inicialmente, afetadas por fraturas poligonais resultantes de arrefecimento, tendo sido posteriormente reativadas devido às tensóes compressivas homogéneas resultantes do alargamento térmico. Em relaçáo à Terra, no que diz respeito aos terrenos poligonais do Arizona (região de clima quente e seco), e tendo em conta que também o nosso planeta, e mais especificamente esta região, terá passado por um cenário de variação climática, por comparação, é expectável que os valores obtidos fossem em tudo bastante semelhantes.

Nos polígonos terrestres que resultam de contração térmica, a morfologia está claramente dependente das propriedades reológicas da subsuperfície (incluindo a presença de gelo) e dos fatores ambientais à superfície, incluindo a presença (ou ausência) de estratos ativos saturados (PEWE, 1959; LACHENBRUCH, 1961; MALOOF et al., 2002; MARCHANT \& HEAD, 2007).

Em climas frios e húmidos, nos quais a presença de estratos dinâmicos é frequente, é usual o desenvolvimento de polígonos em cunhas de gelo (BERG \& BLACK, 1966; WASHBURN, 1973). A clara relação do tipo de polígonos com o clima (e as condições na subsuperfície) significa que os tipos de polígonos formados podem ser considerados como estruturas terrestres estáveis que permitem delinear variaçóes temporais e espaciais das condiçôes ambientais locais (BLACK, 1952; MARCHANT \& HEAD, 2007).

Assim, e mais uma vez, sabendo que o estudo das formas e morfologias presentes nos planetas é feito através de um processo de comparação com estruturas existentes no planeta Terra, pode-se estabelecer um paralelismo com as condiçóes de formação dos polígonos marcianos, podendo chegar-se, a partir daqui, à conclusão de que os resultados obtidos são, de novo, análogos quando comparados entre si.

Pode-se então concluir que estas estruturas geológicas particulares, que envolvem processos de formação em condiçôes climáticas extremas, foram condicionadas pela atmosfera envolvente e vice-versa.

Pela análise da primeira linha da Tabela 1 e comparando a mediana do número de lados dos polígonos de Svalbard e de Marte, conclui-se que esta é igual (4 lados), mas diferente da mediana do número de lados dos polígonos do Arizona e de Vénus (5 lados), como consequência, igualmente, do clima envolvente.

A dimensão fratal é uma importante característica geométrica dos objetos geológicos. Esta é uma medida do grau de irregularidade e de fragmentação (MANDELBROT, 1991).

Uma das técnicas mais usadas para calcular a dimensão fratal de um objeto é o método da contagem de caixas (TURCOTTE, 1997), que foi usado para produzir os dados da segunda linha da Tabela 1.

A dimensão fratal das redes poligonais volta a confirmar claramente uma discriminação climática, com os climas frios a produzirem dimensóes em torno de 1,5 e os quentes de 1,75 . 
Tabela 1 - Parâmetros geométricos dos polígonos estudados.

\begin{tabular}{rcccc} 
& Vénus & Arizona (Terra) & Marte & \multicolumn{2}{c}{ Svalbard (Terra) } \\
\hline Mediana do no de lados & 5 & 5 & 4 & 4 \\
Dimensão fratal & 1,72 & 1,79 & 1,50 & 1,52 \\
\hline
\end{tabular}

\section{3 - Conclusóes}

O regime climático tem implicaçóes para a geologia e para a geofísica dos planetas telúricos.

Tendo-se estabelecido alguns parâmetros caracterizadores tais como área, perímetro e tipo de rede de polígonos, contexto geológico e ocorrência de outras estruturas, todos eles fortemente relacionados com o clima, conclui-se que é grande a influência da interação litosfera/atmosfera na formação de padrôes poligonais, nos três planetas telúricos amostrados.

Os dados obtidos com o estudo de outros corpos planetários pertencentes ao Sistema Solar contribuem, cada vez mais, para um melhor conhecimento dos fenómenos terrestres, do mesmo modo que um melhor conhecimento destes aprofunda a compreensão do Sistema Solar.

Agradecimentos - Este trabalho foi financiado pela Fundação para a Ciência e a Tecnologia, ao abrigo do contrato PEst-OE/CTE/UI0611/2012 - Centro de Geofísica da Universidade de Coimbra (CGUC).

\section{Referências Bibliográficas}

ALVES, E. I. (2010) - Pequeno atlas do Sistema Solar. Imprensa da Universidade de Coimbra.

BERG, T. E. \& BLACK, R. F. (1966) - Preliminary measurements of growth of nonsorted polygons, Victoria Land, Antarctica. In: Tedrow, J. C. F. (eds.). Antarctic Soils and Soil-Forming Processes. Antarctic Research Series, Washington, 8, p. 61-108.

BLACK, R. F. (1952) - Polygonal patterns and ground conditions from aerial photographs, Photogramm. Eng., 17 , p. $123-134$.

BULLOCK, M. A. \& GRINSPOON, D.H. (2001) - The recent evolution of climate on Venus. Icarus 150, p. 19-37.

GOOGLE INC. (2012) - Google Earth (Version 6.2.2.6613) [Software].

MANDELBROT, B. (1991) - Objectos fractais - Forma, acaso e dimensöes. Gradiva. Lisboa.

MALOOF, A. C., KELlOGG, J. B. \& ANDERS, A. M. (2002) - Neoproterozoic sand wedges: Crack formation in frozen soils under diurnal forcing during a snowball Earth, Earth and Planetary Science Letters, 204, p. 1-15.

MARCHANT, D. R. \& HEAD, J. W. (2007) - Antarctic Dry Valleys: Microclimate zonation, variable geomorphic processes, and implications for assessing climate change on Mars, Icarus, 192, p.187-222.

LACHENBRUCH, A. H. (1961) - Depth and spacing of tension cracks, Journal of Geophysical Research, 66, p. 4273-4292. 
NASA (2012) - Planetary Data System, http://pds.nasa.gov/ [consultado em 2012.02.22]

PEWE, T. L. (1959) - Sand-wedge polygons (tessellations) in the McMurdo Sound region, Antarctica-A progress report, American Journal of Science, 257, p. 545-552.

SMREKAR, S. E., MOREELS, P. \& FRANKLIN, B. J. (2002) - Characterization and formation of polygonal fractures on Venus. Journal of Geophysical Research, 107, p. 8-1 - 8-18.

TURCOTTE, D. L. (1997) - Fractals and Chaos in Geology and Geophysics, 2nd ed. Cambridge Univ. Press.

WASHBURN, A. L. (1973) - Periglacial Processes and Environments. St. Martin's Press, New York. 